\title{
Dynamic Downscaling of Rainfall Data for Deduru Oya River Basin using WRF Weather Model
}

\author{
S.M.T.C. Samarasingha, M.S. Sandaruwan, D.S. Sampath and N.G.P.B. Neluwala
}

\begin{abstract}
Flood warning and effective radial gate operations of Deduru Oya reservoir are important in flash flood controlling and reducing the impact of flash floods. Future rainfall forecast is essential to obtain runoff forecast into the reservoir and for the hydrological modelling. A limited number of studies have been conducted on weather forecasting in Sri Lanka. This study proposes a weather forecasting model for the basin using Weather Research and Forecast (WRF) model. WRF model was optimized by doing a series of simulations with multiple microphysics and cumulus physics parametrization schemes. Optimum physics combinations were identified considering two extreme rainfall events on 2 November 2015 and 16 May 2016, and the results were validated for the extreme rainfall event on 1 September 2017. WSM3 and Betts-Miller-Janjic cumulus schemes were found to be the optimum parameterization schemes for microphysics and cloud microphysics, respectively. The developed model can be used for weather forecasting in the region.
\end{abstract}

Keywords: $\quad$ Deduru Oya river basin, WRF, Dynamic downscaling, Rainfall forecasting

\section{Introduction}

Deduru Oya is the $4^{\text {th }}$ largest river basin in Sri Lanka which has an area of $2620 \mathrm{~km}^{2}$ and extending from Chilaw in the west coast to the central hills at Matale. The basin boundaries are Mee Oya basin to the north, central hills to the east, Maha Oya basin to the south and coast to the west [12].

Due to steep slopes and heavy rainfall in the upper parts of the Deduru Oya basin, Deduru Oya downstream experiences flash floods frequently [11]. Flash flood control is one of the aims of the Deduru Oya reservoir construction [9]. Flood warning and effective radial gate operations are important for flash flood control and reducing the impact of a flash flood. Radial gate operation needs to be alerted in advance based on future runoff into the reservoir, and the future rainfall data is essential to obtain future runoff into the reservoir.

Numerical weather models can estimate weather conditions such as precipitation, wind velocity, temperature. Global Climate Models (GCMs) are used to simulate global weather and for future climate change projections for various emission scenarios. GCMs describe the atmospheric process using mathematical equations over the whole globe in a $150-300 \mathrm{~km}$ resolution [3].

Due to the low resolution, further downscaling is necessary for regional analysis [6]. This study focuses on dynamical downscaling using
Weather Research and Forecasting (WRF) model which is a Regional Climate Model (RCM) to downscale the weather conditions to a predefined limited area using the boundary conditions from GCMs.

The WRF model contains a number of different physics parameterizations, allowing to include the effects of significant weather processes such as microphysics, cumulus physics, surface layer physics, planetary boundary layer physics, land surface physics and radiation physics. The physics parameters were varied during model calibration [8]. Accordingly, the most effective set of physics parameters were chosen before the model was applied for any operational purposes.

Mr. S.M.T.C. Samarasingha, B.Sc. Eng. (UG.) (Jaffna), Final Year Student, Department of Civil Engineering, University of Jaffna, Kilinochchi, Sri Lanka.

Email:2016e043@eng.ifn.ac.lk

Mr. M.S. Sandaruwan, B.Sc. Eng. (UG.) (Jaffna), Final year Student, Department of Civil Engineering, University of Jaffna, Kilinochchi, Sri Lanka.

Email:2016e044@eng.jfn.ac.lk

Eng. D.S. Sampath, AMIE(SL), B.Sc. Eng. (Hons.) (Peradeniya), M. Phil. (Peradeniya), Senior Lecturer, Department of Civil Engineering, University of Jaffna, Kilinochchi, Sri Lanka.

Email:saliya@eng.jfn.ac.lk

Eng. (Dr.) N.G.P.B. Neluwala, AMIE(SL), B.Sc. Eng. (Hons.) (Peredeniya), Ph.D. (Tokyo), MEng. (Tokyo), Senior Lecturer, Department of Civil Engineering, University of Peradeniya, Sri Lanka.

Email:pandukaneluwala@eng.pdn.ac.lk

ORCID ID: $h$ ttp://orcid.org/0000_0002_1686_3412 
There are a limited number of studies on weather forecasting over Sri Lanka and none over North Western province. After an intensive literature study, this study is devised to find out the optimum micro and cumulus physics schemes for rainfall prediction over Deduru Oya river basin. This study would be able to fulfill the requirement of rainfall forecast to decision support of Deduru Oya reservoir gate operation.

\section{Literature Review}

\subsection{Climate Downscaling}

GCM forecasts are determined on a coarse grid (approximately $150 \mathrm{~km}$ - $300 \mathrm{~km}$ ) and often biased. Therefore, they cannot be directly used in hydrological models to assess the impact of climate change forecast in finer grids [3]. Thus, further downscaling is needed. There are two main approaches to downscaling as dynamical and statistical downscaling.

In dynamical downscaling, a regional climate model (RCM) is nested covering the interested region within a GCM. RCMs use time varying atmospheric boundary conditions around a finite domain from the GCM. RCMs have been widely applied and well recognized as an essential tool to address scientific issues concerning climate variability, changes and impacts at regional and local scales. Numerous RCMs are available yet many model deficiencies remain to be resolved [15].

In statistical downscaling, the relationship between a large-scale model and a local climate is determined using statistical methods. Statistical downscaling methods are computationally inexpensive (compared to the dynamic downscaling) and can be applied to output from GCM or RCM [13]. The main assumption is that the relationship between large and local scales will remain unchanged in the future which may not hold always [3].

\subsection{Recent Studies Using RCMs to Forecast Weather}

The WRF model has been used to model the weather over Nilwala river basin [8]. It was configured to predict rainfall for $24 \mathrm{~h}$ into future over the domain. The impacts of microphysics scheme, cumulus schemes, land surface schemes, long/short wave schemes and boundary layer schemes on rainfall prediction were observed and found that the combination of Ferrier microphysics scheme, Kain-Fritch cumulus scheme, Rapid Update Curve (RUC) land surface scheme, Rapid Radiative Transfer Model, longwave radiation scheme, Dudhia shortwave scheme and Yonsei boundary layer scheme have been accountable for a better precipitation prediction over Nilwala river basin. This study investigated physics parameters separately, considering default options of other physics schemes.

WRF model has been applied to the Kelani river basin Sri Lanka with a $24 \mathrm{~h}$ forecast time for three extreme rainfall events, 21 November 2005, 01 June 2008 and 18 July 2008 [2]. By a comparison of predicted rainfall with observed rainfall of 10 selected rain gauge stations, it has been found that the simplified arakawa cumulus parameterization scheme with Lin et al microphysics scheme, RUC Land surface model, Asymmetric Convective Model (ACM2) planetary boundary layer physics and other default physics options produce reasonable predictions. For the comparison, the WRF output was spatially distributed with $3 \mathrm{~km} \times 3$ $\mathrm{km}$ grids and also the observed point rainfall data were spatially distributed on $3 \mathrm{~km} \times 3 \mathrm{~km}$ horizontal grids and compared using the GIS based Inversed Distance Weighting (IDW) technique. This study was carried out only for five different cumulus physics schemes with default options for other physics.

An experiment was carried out to capture the heavy rainfall that occurred from 18 to 27 December 2014 which resulted in one of the worst flood events in the Sri Lanka. The experiment was conducted considering six different combinations of the cumulus and the microphysics parameters which are important for capturing rainfall extreme events using WRF model [1].

A study has been conducted to compare the performance of the rainfall downscaling with the WRF and RegCM (Regional Climate Model) models considering the upper Mahaweli river basin [7]. There, the models have been evaluated by considering three past rainfall extreme events and found that the WRF model predicts rainfall with a higher accuracy than the RegCM model.

Among the numerical weather prediction models, WRF model is commonly used in most of the studies [10]. Only a few regions of Sri Lanka have been analysed using WRF model and there are no rainfall prediction models developed for Deduru Oya river basin at the moment. 


\subsection{Physics Scheme Parameters}

Microphysics and the cumulus physics parameters are sensitive to the numerical weather prediction over tropical areas [8]. Therefore, before operational purposes, the model output should be evaluated for multiple microphysics and cumulus physics parameters to find the optimum physics parameters [10].

Microphysics includes certain water vapour, cloud and precipitation processes. There are a number of microphysics such as Kessler scheme, Lin et al scheme, WRF Single Moment 3-class (WSM3) scheme, WSM5 scheme, WSM6 scheme, and Ferrier scheme [8].

Kessler scheme implemented the processes of production, fall, evaporation of rain, and the production of cloud water by condensation. Lin et al scheme utilizes the water vapour, cloud water, cloud ice, rain, snow, and graupel. WSM3 scheme uses water vapour, cloud water/ice, and rain/snow. Cloud water and cloud ice, as well as rain and snow are distinguished by the temperature. WSM5 physics scheme is same as the WSM3 physics scheme except it allows the existence of supercooled water and the gradual melting of snow to rain as it is fallen towards the space. WSM6 scheme is similar to the WSM5 but includes graupel as another variable [10].

Cumulus Parameterization schemes are responsible for the sub grid scale effects of convective and/or shallow clouds and theoretically valid only for coarser grid sizes. The types of cumulus parameterization schemes are Kain-Fritsch scheme, Betts-Miller-Janjic scheme, Grell-Devenyi ensemble scheme, and Simplified Arakawa scheme [2].

Kain Fritsch cumulus scheme redistributes the mass in the grid column such as convective available potential energy. Betts-Miller-Janjic cumulus scheme adjusts the profiles towards a predetermined, post convective reference profile derived from climatology. Grell-Devenyi cumulus scheme includes the cloud ice and detrainment. Simplified arakawa cumulus scheme includes the effect of moisture detrainment from convective clouds, warming from environmental subsidence and convective stabilization in balance with the large scale destabilization rate [10].

\section{Methodology}

\subsection{Model}

The WRF model is a mesoscale numerical weather prediction system designed to serve both atmospheric research needs and operational forecasting. It includes several dynamic cores, a 3-dimensional variation (3DVAR) data assimilation system and a software architecture allowing for computational parallelism and system extensibility [2].

\subsection{Model Preparation}

The model domain was configured with the use of 'Domain Wizard' as the geographical data resolution of the master domain with $10 \mathrm{~km}$ resolution, second nested domain with $5 \mathrm{~km}$ resolution covering the whole Sri Lanka and the third nested domain with a resolution of $2 \mathrm{~km}$ focusing the Deduru Oya river basin. The basin is located between Northern latitude $7^{0} 19^{\prime} 00^{\prime \prime}$ to $7^{\circ} 52^{\prime} 00^{\prime \prime}$ and Eastern longitude $79^{\circ} 47^{\prime} 00^{\prime \prime}$ to $80^{\circ} 35^{\prime} 00^{\prime \prime}$ and it has an area of $2620 \mathrm{~km}^{2}$ with elevation ranging from $0 \mathrm{~m}$ to $1280 \mathrm{~m}$ MSL [12].

The model domain setup containing the three nested domains are shown in Figure 1.

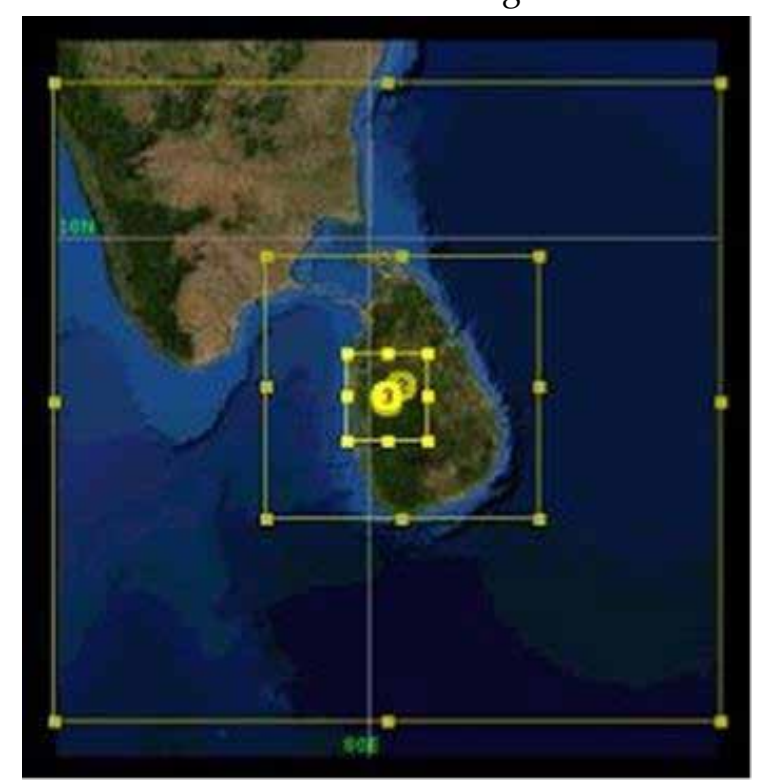

Figure 1 - Domain Setup

To fine tune the model, 24 different sets of physics parameters were defined considering the Kessler, Lin et al, WSM3, WSM5, and Ferrier microphysics parameters and the KainFritsch, Betts-Miller-Janjic, Grill-Devene, and simplified arakawa cumulus physics parameters as shown in Table 1. 


\begin{tabular}{|c|c|c|c|c|c|c|c|}
\cline { 3 - 7 } \multicolumn{2}{c|}{} & \multicolumn{7}{c|}{ Microphysics Schemes } \\
\cline { 2 - 8 } \multicolumn{2}{c|}{} & Kessler & Lin et al & WSM3 & WSM5 & Ferrier & WSM6 \\
\hline $\begin{array}{c}\text { Cumulus } \\
\text { Physics } \\
\text { Schemes }\end{array}$ & Kain-Fritsch & Set 1 & Set 2 & Set 3 & Set 4 & Set 5 & Set 6 \\
\cline { 2 - 8 } & $\begin{array}{c}\text { Betts-Miller- } \\
\text { Janjic }\end{array}$ & Set 7 & Set 8 & Set 9 & Set 10 & Set 11 & Set 12 \\
\cline { 2 - 8 } & Grell-Deveny & Set 13 & Set 14 & Set 15 & Set 16 & Set 17 & Set 18 \\
\cline { 2 - 9 } & Arakawa & Set 19 & Set 20 & Set 21 & Set 22 & Set 23 & Set 24 \\
\hline
\end{tabular}

\subsection{Model Calibration}

Optimum physics combinations were identified considering two heavy rainfall extreme events on 02 November 2015 and 16 May 2016 for the model performance evaluation. Observed point rainfall data were collected from Kurunegala, Millawana, Wariyapola, Nikaweratiya, Ridibendiela and Polonthalawa rain gauge stations. Then the WRF output and observed point rainfall data were spatially distributed with $5 \mathrm{~km} \times 5 \mathrm{~km}$ horizontal grids with the use of Inverse Distance Weighting (IDW) technique of the ArcGIS software and the observed rainfall data were compared with the predicted rainfall data with the use of Mean Absolute Model Error percentage (MAME\%) [7] as in Eq. (1).

$M A M E \%=((S R-O R) /(O M R)) \times 100 \%$

where,

$S R$ - Simulated rainfall

$O R$ - Observed rainfall

OMR - Observed mean rainfall

\subsection{Model Validation}

Model validation was performed for the selected extreme event on 01 September 2017, considering Betts-Miller-Janjic cumulus and WSM3 microphysics parameters with default options for other physics schemes (Set 9). The observed rainfall data of the selected rain gauge stations and the predicted rainfall data were compared using IDW tool of ArcGIS software by distributing both sets of data into $5 \mathrm{~km} \times 5$ $\mathrm{km}$ grids over the basin similar to calibration step.

\section{Results and Discussion}

Figure 2 shows the percentage of cumulative correctly predicted area (CCPA \%) within $50 \%$ of MAME \% over the basin for all the selected 24 sets of physics schemes for model calibration considering the selected extreme events on 02 November 2015 and 16 May 2016.

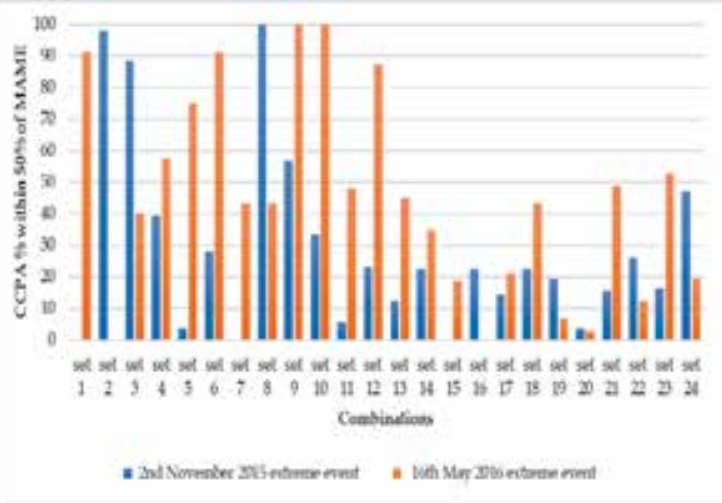

Figure 2 - ССРА $\%$ within $50 \%$ of MAME $\%$

The average values of CCPA \% within $50 \%$ of MAME \% for selected two extreme events are shown in the Figure 3.

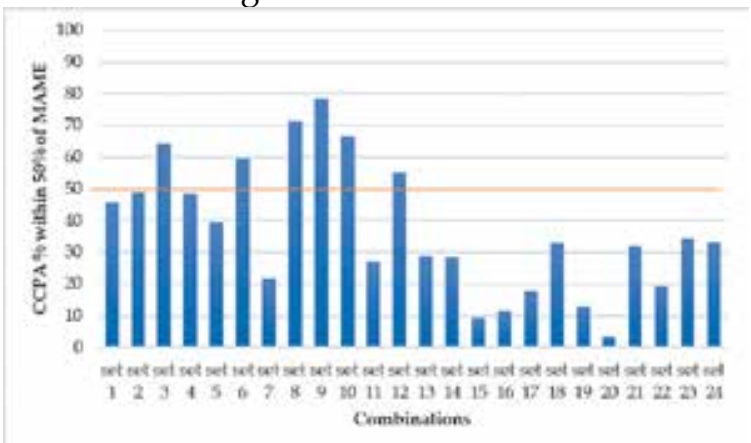

Figure 3 - Average of CCPA \% within $50 \%$ of MAME \%

According to Figure 3, the average of CCPA \% within $50 \%$ of MAME \% was higher than $60 \%$ in set 3 with WSM3 microphysics and Kain Fritsch cumulus physics options, set 8 with Lin et al microphysics and Betts-Miller-Janjic cumulus physics options, set 9 with WSM3 microphysics and Betts-Miller-Janjic cumulus physics options, and set 10 with WSM5 microphysics and Betts-Miller-Janjic cumulus physics options. Accordingly, set 3, set 8 , set 9, and set 10 were the best combination among the selected combination sets for the prediction of rainfall over Deduru Oya river basin. The graphical plots of correctly predicted area with MAME \% for the selected four sets are shown in Figure 4. 
02nd Nov 2015
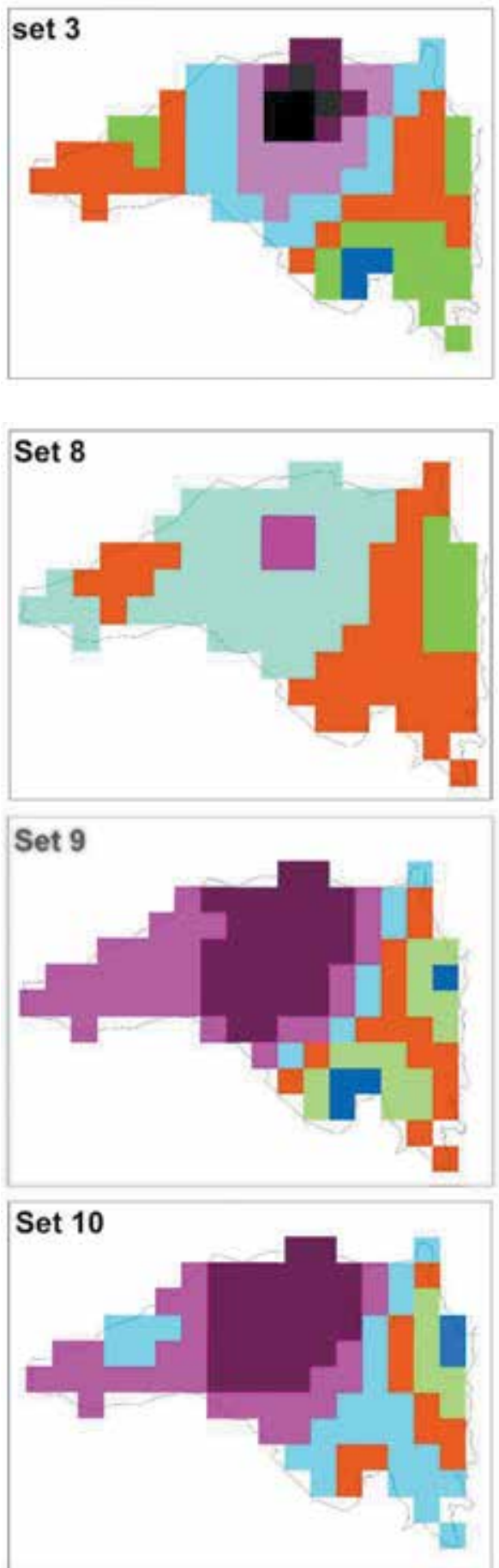

\section{Legend}

within $10 \%$ range of MAME $\%$ within $10-20 \%$ range of MAME $\%$ within $20-30 \%$ range of MAME $\%$ $16^{\text {th }}$ May 2016
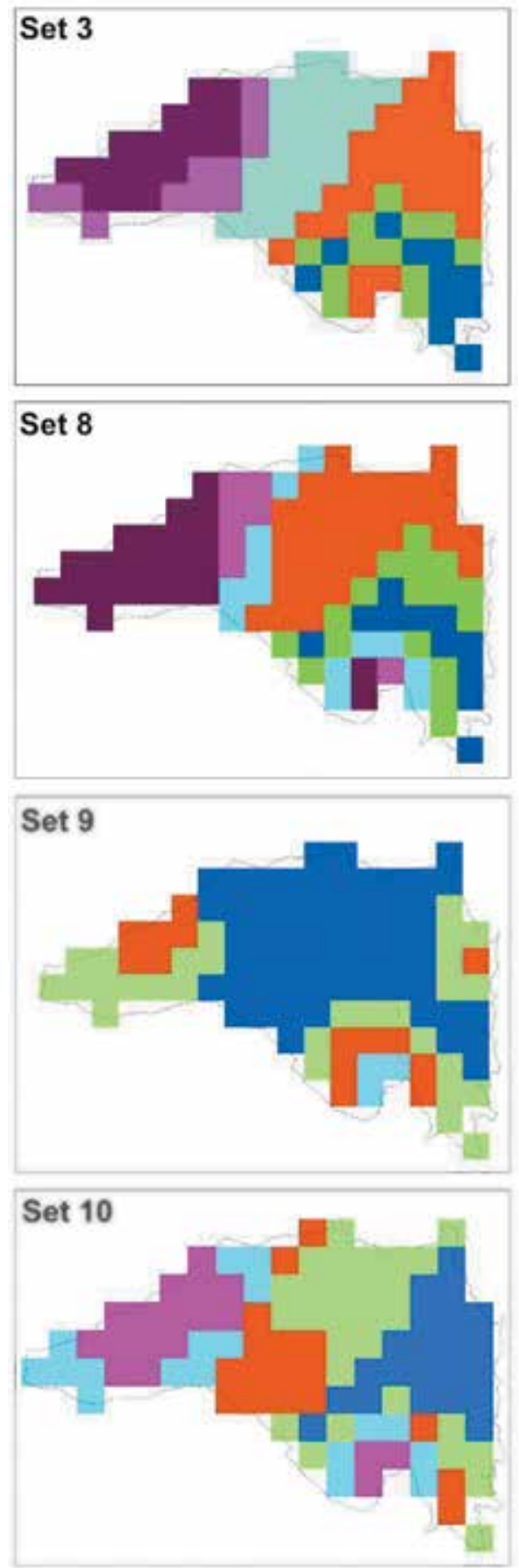

within $30-40 \%$ range of MAME $\%$

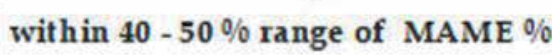
over $50 \%$ range of MAME $\%$

Figure 4 - Correctly Predicted Area with MAME \% for Model Calibration 
A given colour in Figure 4 represents MAME \% ranges. Among those four selected sets, three of them contain Betts-Miller-Janjic cumulus physics and two of them contain WSM3 microphysics schemes. According to that representation, Betts-Miller-Janjic cumulus physics, WSM3 microphysics scheme with default options for other physics parameters were selected to the proceeding of the model validation test.

The model validation was performed for the rainfall extreme event on 01 September 2017 with the consideration of WSM3 microphysics scheme and Betts-Miller-Janjic cumulus physics scheme with default options for other physics schemes. The model has predicted correctly $85.58 \%$ of CCPA \% within $50 \%$ of MAME \% over the basin according to Table 3 and the graphical plot of the correctly predicted area with MAME \% for the model validation is shown in Figure 5.

Table 2 - Correctly Predicted Area \% With MAME \% for Model Validation

\begin{tabular}{|c|c|c|}
\hline $\begin{array}{c}\text { Range } \\
\text { difference } \\
\text { (MAME \%) }\end{array}$ & Area \% & $\begin{array}{c}\text { Cumulative } \\
\text { Area (\%) }\end{array}$ \\
\hline $0-10$ & 37.50 & 37.50 \\
\hline $10-20$ & 15.38 & 52.88 \\
\hline $20-30$ & 8.65 & 61.54 \\
\hline $30-40$ & 10.58 & 72.12 \\
\hline $40-50$ & 13.46 & 85.58 \\
\hline$>50$ & 14.42 & 100.00 \\
\hline
\end{tabular}

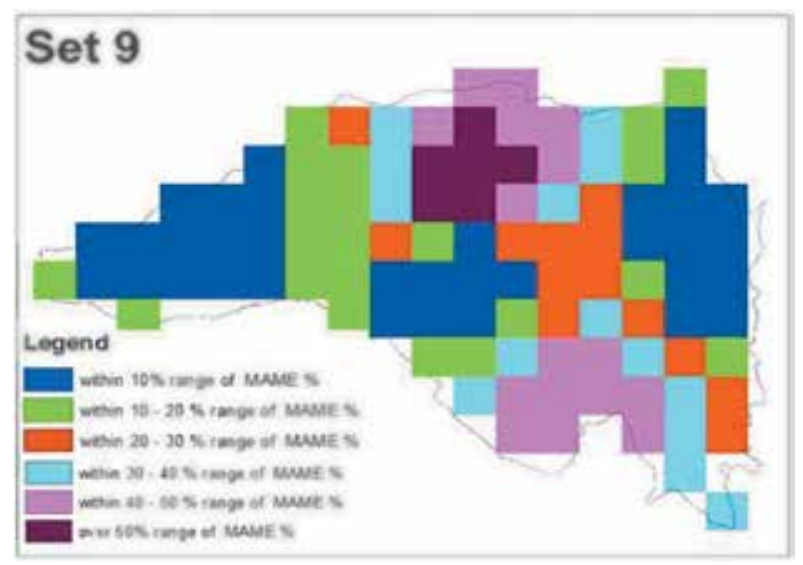

Figure 5 - Predicted Area with MAME \% for Model Validation

\section{Conclusions}

WRF model was set up to forecast the weather for Deduru Oya river basin, Sri Lanka. Predicted rainfall values were compared with the observed rainfall using GIS based IDW technique based on the microphysics and the cumulus physics parameters which are most accountable for the rainfall prediction with the other default parameters for other physics options.

According to the calibration results, the BettsMiller-Janjic cumulus and WSM3 microphysics schemes predicted correctly; $56.7 \%$ of CCPA \% within $50 \%$ of MAME \% for the extreme event on 2 November 2015 and $100 \%$ of CCPA \% within $50 \%$ of MAME \% for the extreme event on 16 May 2016, over the Deduru Oya river basin. According to that the rainfall prediction accuracy of the model is varying with different rainfall events.

The model validation predicted correctly 85.58 $\%$ of CCPA \% within $50 \%$ of MAME \% for Betts-Miller-Janjic cumulus and WSM3 microphysics schemes with other default parameters for other options for the selected rainfall extreme event on 01 September 2017.

This study concludes that the Betts-Miller-Janjic cumulus and the WSM3 microphysics options with default parameters for other options yield the best rainfall prediction over Deduru Oya river basin out of the tested combinations.

This experiment was limited to two physics parameter sets and further accurate predictions can be achieved with the consideration of other physics scheme parameters with the WSM5 microphysics and Betts-Miller-Janic cumulus physics scheme parameters for the study area of Deduru Oya river basin and doing further experiments for more rainfall extreme events over the basin. It is anticipated that studying each season separately will give more accurate results.

Developed model can be used to predict the future rainfall data for Deduru Oya river basin and those data can be used for flood control activities through optimum radial gate operations of Deduru Oya reservoir.

\section{References}

1. Darshika, D. W. T. T. \& Premalal, K. H. M. S., “Simulate Heavy Rainfall During 19th to 28th December 2014 Using WRF for Different Atmospheric Physics", Department of Meteorology, 2014, pp. 32-40.

2. De Silva, G., Herath, S., Weerakoon, S. \& Rathnayake, U., "Application of WRF With Different Cumulus Parameterization 
Schemes for Precipitation Forecasting In a Tropical River Basin", Proceeding of $13^{\text {th }}$ Asian Congress of Fluid Mechanics, Dhaka, Bangladesh, 2010, pp. 513-516.

3. Fowler, H. J., Blenkinsop, S. \& Tebaldi, C., "Linking Climate Change Modelling To Impact Studies: Recent Advances In Downscaling Techniques for Hydrological Modelling", International Journal of Climatology, Vol. 27, No. 12, 2007, pp. 15471578.

4. Hashmi, M. Z., Shamseldin, A. Y. \& Melville, B. W., "Statistical Downscaling of Precipitation: State of the Art and Application of Bayesian Multi- model Approach for Uncertainty Assessment", Hydrology and Earth System Sciences Discussions, vol. 6, no. 5, 2009, pp. 6535-6579.

5. Inter-governmental Panel on Climate Change (IPCC).2007. "Climate Change 2007": Synthesis Report.

6. Mallard, M. S., Nolte, C. G., Bullock, O. R., Spero, T. L. \& Gula, J., “Using a Coupled Lake Model with WRF for Dynamical Downscaling", Journal of Geographical Research: Atmospheres, 2014, pp. 7193-7208.

7. Muhinadeen, M., Khalid, M. M., Weerakoon, S. B. \& Mutua, F., "Comparative Study of WRF \& REGCM Weather Predictions for the Upper Mahaweli River Basin", $7^{\text {th }}$ International 2016, 2016, pp. 140-145.

8. Nandalal, K. D. W., Sachindra, D. A. \& Ratnayake, U. R., "Application of WRF Weather Model to Forecast Precipitation in Nilwala River Basin", Engineer: Journal of the Institution of Engineers, Sri Lanka, vol. 45, no. 1, 2012, pp. 51-64.

9. Samarakoon, S. M. L. D., Dayawansa, N. D. K. \& Gunawardena, E. R. N., "Land Use Changes Resulting from Construction of Deduru Oya Reservoir and It's Impacts on Livelihood", Tropical Agricultural Research, vol.28(2), 2017, pp. 162-174.

10. Sonkaew, T., Cumwan, S., Kanta, W. \& Macatangay, R., "Finding the Optimum Microphysics and Convective Parameterization Schemes for the WRF Model for LPRU, Thailand", Siam Physics Congress 2016 Proceedings, Thailand, 2016, pp. 243-253.

11. Somarathne, P. G., Jinapala, K., Perara L. R., Ariyarathne, B. R., Bandaragoda, D. J \& Makin, I. W., "Developing Effective Institution for Water Resources Management: A Case Study in the Deduru
Oya Basin, Sri Lanka", International Water Management Institute, Colombo, Sri Lanka, 2003, pp. 98.

12. Weerakoon, S. B., Sampath, S. and Herath, S.," Irrigated Water Resources Analysis of the Deduru Oya Left Bank Considering Traditional and Modern Systems", Resilient Asia, 2018, pp. 123-149.

13. Wilby, R. L., Charles, S. P., Zorita, E., Timbal, B., Whetton, P. \& Mearns, L. O., "Guidelines for Use of Climate Scenarios Developed from Statistical Downscaling Methods: Supporting Material of the Intergovernmental Panel on Climate Change Prepared on Behalf of Task Group on Data and Scenario Support for Impacts and Climate Analysis", Intergovenmental Panel on Climate Change Report, 2004, pp. 1-27.

14. Xu, C. Y. \& Singh, V. P., "Review on Regional Water Resources Assessment Models Under Stationary and Changing Climate", Water Resources Management, vol. 18, no. 6, 2004, pp. 591-612.

15. Xu, Z., Rhoades, A. M., Johansen, H., Ullrich, P. A. \& Collins, W. D., "An Intercomparison of GCM and RCM Dynamical Downscaling for Characterizing the Hydroclimatology of California and Nevada", Journal of Hydrometeorology, 2018, pp.1485-1506. 